\title{
Risk Factors of the COVID-19 Pandemic in the Development of Preschool Children and Protective Factors
}

\author{
Neslihan Durmuşoğlu Saltalı 1 \\ ${ }^{1}$ Ordu University, Faculty of Education, Preschool Education Department, Ordu, Turkey \\ ndsaltali@gmail.com
}

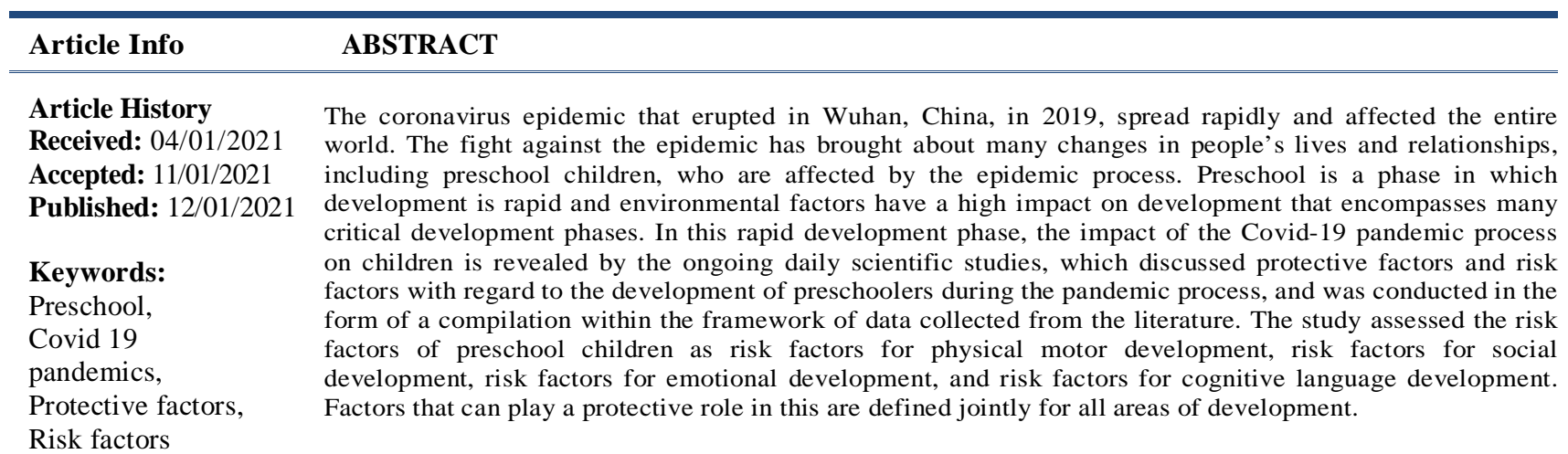

Citation: Durmuşoğlu Saltalı, N. (2021). Risk factors of the covid-19 pandemic in the development of preschool children and protective factors. Journal of Teacher Education and Lifelong Learning, 3(1), 1-8. 


\section{INTRODUCTION}

It emerged in 2019 in Wuhan city of China, in March 2020 the first cases seen in Turkey coronavirus outbreak was under the influence spread all over the world in a short time. The epidemic, which was quickly declared a pandemic by the World Health Organization (WHO), has brought about many changes in human life, health, living conditions, the economy, psychology, and human relations (Romero, Lopez-Romero, Dominguez-Alvarez, Villar \& Gomez-Fraguela, 2020), affecting people of all ages and professions in different ways. During the epidemic, preschool-age children are among the individuals most affected by the stage of development in which they find themselves. Pre-school is a stage in which development is rapid, involves many critical stages of development, and the impact of environmental factors on development is high. In periods of rapid development, changes in the child's life can be a risk factor that can negatively affect the development (Ghosh, Dubey, Chatterjee \& Dubey, 2020). However, the positive behaviors, appropriate practices, and preventive interventions that adults around the child engage in this process can also become a protective factor that reduces or eliminates the effects of the pandemic (Racine et al. 2020). In this study, the risk factors that may occur in the development of preschool children due to the covid 19 pandemic and the factors that may play a protective role were investigated on the basis of the literature. Risk factors are presented as risk factors for physical and motor development, risk factors for social development, risk factors for emotional development, and risk factors for cognitive and linguistic development. Physical development and motor development, cognitive development, and language development are presented together because they are areas of development that interact very intensively with each other and the risk factors presented affect these areas in a similar way.

\section{Risk factors of physical and motor development}

Physical and motor development in early childhood is closely related to an individual's health status. Risk factors for physical and motor development are diseases such as sleep disturbances, mistakes in the use of masks, the risk of inactivity and obesity, unhealthy eating, reduced opportunities to play outdoors, which can pose a risk to the individual's health due to the Covid 19 pandemic.

Sleep disorders: Sleep is just as important and indispensable in human life as breathing, eating, and excretion and is the basic condition for health. Sleep is also a very important habit for the growth and development of the child (Murthy, Bharti, Malhi \& Khadwal, 2015). Sleep habits are among the habits that families struggle with while having children (Lavigne et al. 1999). Practices such as interrupting education in some countries during the pandemic process and changing parents' working patterns and working hours, some of which are converted to flexible working models, some working from home, can change the sleeping habits of children in some families. Families tend to violate the rules they set during their sleeping and waking hours, which can lead to a deterioration in sleeping habits and make sleeping habits an important risk factor for the physical development, motor development and health of the child.

Mistakes in the use of masks: The use of masks is one of the key measures for the prevention of coronavirus infections (Bicen \& Erturk, 2020). However, if some questions regarding the use of masks are not taken into account, the use of masks due to misuse can also become an important risk factor that endangers development and health found that the use of masks over a long period of time in activities that require intensive exercise is risky for health (Epstein et al. 2020). Pre-school is a time when children's need for movement is intense. During the pandemic process, children go to the fresh air for limited hours and can play games with intense movement during these hours. Performing activities that require intensive movement in masks over a long period of time may be an important risk factor, especially for people with heart disease (Yalcin, 2020). Another situation that can make the use of masks a risk factor is the risk of infection that masks carry when worn for long hours. There is information in the literature that long-term and repeated use of masks may pose a risk for the individual to infect himself and others (WHO, 2020; Yalcin, 2020). There are suggestions for changing the mask, especially when it is moist (WHO, 2020). Using masks over long 
periods of time without taking these recommendations into account can lead to health risks, particularly from infections. Apart from the fact that if children do not wear the mask correctly, touch the outside of the mask and change the mask between them, the mask whose main purpose is protection can become a risk factor.

Exercise deficiency and obesity: One of the most important factors for the physical and motor development of the child is the freedom of movement (Akyol, Bilgic, \& Ersoy, 2008). The fact that children have to spend most of their time indoors due to the curfew imposed during the pandemic is a very restrictive situation in terms of movement and it is very difficult to perform activities such as jumping, jumping, running or balance movements, which are important for the development of large muscular motor skills, in the home environment. This restriction of movement can become an important risk factor for physical and motor development due to the negative effects of both the growth and muscle development of children and the risks of obesity and diseases such as chronic diseases and muscle diseases. If these sedentary lifestyles are maintained after the pandemic, all the risks that may arise can reach more significant dimensions for human health.

Unhealthy nutrition: One of the risk factors that can hinder or negatively affect the physical and motor development of the child is an unhealthy nutrition (Arli, Sanlier, Kucukkomurler \& Yaman, 2017). Since pre-school is a period in which growth and development continue, unhealthy eating during this period is a risk factor that can cause disturbances in the physical and motor development of the child.

Less opportunity for outdoor play: The increasing interest of researchers in extracurricular learning environments has also drawn attention in recent years to outdoor activities (Alhassan, Sirard, \& Robinson, 2007; Aktas Arnas \& Sarıbas, 2020; Lundy \& Trawick-Smith, 2020). MoNE 2013 Preschool Program Book also draws attention to the importance of outdoor activities and recommends not relying on the classroom for planning activities and using garden facilities at the highest level. Playing outdoors is an important activity that gives the child the opportunity to move in the fresh air and move freely. Restrictions experienced during the pandemic process can become a developmental risk factor as children reduce their ability to play outdoors.

\section{Risk factors for social development}

In terms of the social development of the child in the preschool period, establishing relationships with people of different age groups and observing and modeling relationships between other people has an important place (Gulay, 2009). Risk factors from the perspective of social development in pre-school were assessed on the basis of the child's relationships with people and disturbances in friendships, kinship and neighborly relationships were discussed.

Disturbances in the relationship with friends: Preschool is a critical time for the socialization of the child as well as for all areas of development. In this time, friendship relations have an important place both in terms of the socialization of the child and the right to play (Wang, Palonen, Hurme \& Kinos, 2019). However, the nature of the fight against the pandemic, which limits human relations, has also interrupted the friendships of the children. This situation may become an even more important risk factor for social development, especially for children without siblings.

Disturbances in kinship relations: One of the most important relationships in terms of social development is kinship relations. One of the issues highlighted in the literature is that in recent years there has been a weakening of kinship relations due to reasons such as migration from the village to the city, changes in family structure, working conditions of families regardless of the pandemic (Abay \& Demir, 2014). In addition to this weakening, it is thought that the disorders that can occur as a result of the pandemic can shake relations between relatives and, in this case, could be an important risk factor for both the social development of the child and the social structure.

Neighborly relationships disruptions: One of the relationships affected by the pandemic is neighborly relations, which have an important place in pre-school life for children to acquire values such as 
cooperation, solidarity and solidarity and to observe social relationships, but just like kinship in society, it is one of the relationships that has weakened in recent years, especially in cities (Abay \& Demir, 2014). It should not be forgotten that pandemic disturbances in neighborhood relations, which are currently tending to weaken, may pose a risk in terms of socialization and the assumption of social roles for preschool children.

\section{Risk factors for emotional development}

Fear, anxiety, guilt: Isolation at home due to the precautions taken in the context of the pandemic, domestic conversations about Covid 19 disease, news that is reflected in the media, the presence of sufferers in the immediate vicinity of the child, the possibility of being infected with the virus, the concern of parents towards the child in preschool. For the child, this can be a source of fear and anxiety (Cikrikci, 2020). If the family is not aware of the situations in which the child may be afraid and fearful and the child is insensitive to the emotional state, the perceived fears and anxieties can turn into psychological problems and pose a significant risk to the emotional development of the child. Furthermore, depending on the stage of development at which the child is at, it may think that negative things are due to its erroneous thoughts or behaviors. Thoughts such as the self-guilt of the child for the illness and the illness as punishment for his / her misconduct are an important risk factor for the emotional development of the child. Adults must be aware of this risk.

Difficulties in family relationships due to the pandemic: One of the relationships affected by the pandemic are family relationships (Brown, Doom, Lechuga-Pena, Watamura, \& Koppels, 2020). Especially if one of the parents works in a profession with a high risk of coronavirus, such as a health worker, freight worker, or if the coronavirus test is positive, isolation from the family home or living in a separate house can interrupt the relationship of the child with its parent. Restricting or losing the relationship with the child's parent can be a risk factor that can negatively affect its emotional development if no necessary precautions are taken.

Parental stress: Many changes have also occurred in the lives of adults associated with the pandemic: Parental stress levels may change compared to normal time due to factors such as the weakening of human relationships due to isolation, reduced opportunities for social support, changes in working life and economic difficulties (Brown, Doom, Lechuga-Pena, Watamura, \& Koppels, 2020). There is evidence in the literature that parent stress affects their relationship with the child and increases the possibility of negative behaviors towards the child (Rodriguez-JenKins, \& Marcenko, 2014). Disorders in the parent-child relationship due to the stress caused by the pandemic can become a risk factor for the emotional development of the child.

Dissemination of information that is not suitable for the development of the child: During the pandemic process, speeches about the disease are often used both within the family and in the mass media. In pre-school, the child cannot think abstractly in the cognitive sense and cannot understand certain concepts relating to language development. At this time, communication between parents or the news they watch on television may contain content that can cause anxiety or anxiety in children and jeopardize their emotional development (Brooks et al. 2020).

\section{Risk factors for cognitive and linguistic development}

Increasing use of digital technologies: Factors such as the lack of creative opportunities for families in terms of activities that children will engage in at home during the pandemic process, the need for some parents to work from home, and continuing education activities using digital means during distance learning have increased the use of digital technologies in this process (Cikrikci, 2020). If the use of digital technologies becomes a habit, this is an important risk factor for the cognitive and linguistic development of the child, as well as for all other areas of development and health.

Discontinuation of education: One of the measures taken to combat the pandemic is face-to-face discontinuation of personal education, which has led to efforts to support children pedagogically with opportunities such as distance learning and support from EBA (Ozer, 2020). In cases where face-to-face 
education is not available, alternative education approaches can only be successful if families provide adequate support. However, pre-school education is still a level of education that some parents do not fully understand its importance in our society and that they still perceive as a care service rather than an education level (Can \& Kilic, 2019). However, research on the contribution of pre-school education to development, its role in school preparation and its long-term impact shows the importance of pre-school education. Therefore, in this process, pre-school education services are not supported sufficiently by families at home and inequality of opportunity among children in accessing technological tools may create a developmental risk factor, especially for children from disadvantaged regions.

\section{Protective factors}

Communication in the family: In the environment in which the child is, parents should be attentive in their talk about the disease, the child should be talked about the disease and how to protect it below the level of cognitive and linguistic development, so that it might be possible both for the child to behave appropriately and to prevent the fear that the child might experience as a result of the pandemic (Chanchlani, Buchanan, \& Gill pandemic in 2020). Particularly when it comes to issues such as deaths, unemployment and the closure of care homes, one should be careful, bearing in mind that there can be fears. Also, strong intra-family communication and the ability of the child to easily ask about the issues they are curious about can play a protective role in the development of the child (Dalton, Rapa, \& Stein, 2020).

Healthy nutrition: One of the most effective factors for the physical and motor development of children is a healthy nutrition. Healthy nutrition is important for growth and development, strengthens the immune system and the ability of the body to fight diseases in the event of illness (Arl1, Sanlier, Kucukkomurler, \& Yaman, 2017). Families that consciously behave in terms of adequate and balanced nutrition of the child and regular meals will be an important protective factor for the development of the child (Akseer, Kandru, Keats \& Bhutta, 2020).

Establishing life routines: Since pre-school is a time when habits are established and the importance of routines for the child to feel safe ensures that the child's daily life routines are maintained by the parents during the pandemic process, such as sleep, nutrition, education, play, can give the child strength. It can be a protective factor that conveys the message that has been given and eliminate possible adjustment problems that may arise after the pandemic (Kuru Gonen, 2020).

Educational assistance: During the period when pandemic education is suspended, distance learning support offered by their teachers to children continuing their pre-school and home education activities by families can act as a protective factor by preventing losses that may occur in terms of children's development (Jena, 2020). Supporting children with activities that parents can do at home, such as daily reading of stories, playing with plasticine, art activities after kindergarten broadcast by EBA TV, giving each child the opportunity to receive distance learning, assigning appropriate household responsibilities to the child, translating these into moments of communication and trying to support language development are some of the applications that can be useful.

Relationship maintenance: Man is a social and social being. He must establish and maintain relationships with the people in his community. Maintaining human relations with technological institutions, talking with photos about old memories, talking about the return of life to normality, can be protective for the development of the child, so that the relationship losses caused by the pandemic process have no negative effects during and after the pandemic.

Offering the possibility of expressing emotions: Like all human beings, children can have emotional difficulties during the pandemic process. It is important to offer the child opportunities to express his feelings such as longing and fear. Parents who speak about their feelings and express them appropriately can be a role model for the child. The ability of the child to express his emotions can be a protective factor that can help prevent emotional and behavioral problems that he may experience (Khan, \& Huremović, 2019; Marmarosh, Forsyth, Strauss, \& Burlingame, 2020). 
Walks in nature, outdoor activities: During the pandemic process, the child should be taken by parents for walks in nature with the necessary precautions, during the hours in which they can go out, have the opportunity to spend time outdoors, which provides an opportunity for physical activity in terms of physical-motor development and eliminates the feeling of limitation caused by staying home in terms of emotional development (Mart \& Kesicioglu, 2020; Mart, Alisinanoglu, \& Kesicioglu, 2015). During these walks, parents can also support the child in terms of cognitive and linguistic development by telling stories, talking about what they see, and playing games.

Supporting the right to play: The place and importance of play for the development of the child is an issue that is accepted and agreed upon by the scientific world. Every child has the right to play, such as food, drink, safety and housing rights (Hughes, 2010). The fact that the playground is limited to the home environment during the pandemic process and the playmate restricts it to people living at home should not eliminate the child's right to play. On the contrary, with the creative solutions to be found by parents, constructing indoor games with the child can, if possible, turn a room at home into a playroom, play a protective role by strengthening relationships with the child and supporting the child's right to play what can be a protective role (Mart \& Kesicioglu, 2020).

Indoor sports and exercise activities: Playing sports and exercise-based games in the house to eliminate the problems caused by movement restrictions during the pandemic process by creating a suitable area in which the child can perform movements such as running, jumping, jumping, crawling and sports activities for the parents themselves. As a model from the theme, it will be playing a protective factor role for the development and health of the child (Caner, Unal, Apaydin, Dag, Okur, Kara et al. 2020).

Planning alternative activities: Planning alternative activities such as domestic artistic activities, mandala activities, hobbies, plant breeding, animal feeding for children during the pandemic process can be a resource for the effective use of the child's time and emotional well-being and can act as a protective factor (Kuru Gonen, 2020).

Teaching hygiene rules: Compliance with hygiene rules is an effective factor in preventing diseases. During the pandemic process, hygiene rules, whose vital importance is understood once more, should be explained to the child through games, drama and storytelling in accordance with his developmental level. In addition, providing positive role models on these issues by adults can contribute to the child's development of correct behavior. The child's adoption of hygiene behaviors can be considered as a protective factor on his health and therefore his development.

\section{CONCLUSION}

During the pandemic process, which was handled in the light of the theoretical framework and research results, an attempt was made to evaluate what protective factors might be and what risk factors might be for preschool children. It is believed that the risk factors presented can raise awareness by drawing the attention of families and that protective factors can guide families in doing so. It can also be a guide for assessment studies relating to the relevant risks for the post-pandemic period. 


\section{REFERENCES}

Abay, A., \& Demir, S. A. (2014). Intergenerational social change according to specific parameters (a comparison of family values). Journal of Academic Inquiries, 9(1), 125-151.

Akseer, N., Kandru, G., Keats, E. C., \& Bhutta, Z. A. (2020). COVID-19 pandemic and mitigation strategies: implications for maternal and child health and nutrition. The American Journal of Clinical Nutrition, 112(2), 251256.

Akyol, A. G. A., Bilgic, A. G. P., \& Ersoy, G. (2008). Physical activity, nutrition and healthy lifestyle. Ankara: Klasmat Printing.

Alhassan, S., Sirard, J. R., \& Robinson, T. N. (2007). The effects of increasing outdoor play time on physical activity in Latino preschool children. International Journal of Pediatric Obesity, 2(3), 153-158.

Arlı, M., Sanlier, N., Kucukkomurler, S., \& Yaman, M. (2017). Mother and child nutrition. Pegem Citation Index, 1233.

Aktas Arnas, A. \& Sarıbas, S. (2020). An investigation of pre-school children's and their parents' outdoor play experiences, Pegem Journal of Education and Instruction, 10(2), 373-397.

Bicen, C., \& Erturk, E. (2020). Evaluation of the effects of wearing masks among healthcare professionals during covid-19 pandemic. Electronic Turkish Studies, 15(6), 205-218.

Brooks, S. K., Webster, R. K., Smith, L. E., Woodland, L., Wessely, S., Greenberg, N., \& Rubin, G. J. (2020). The psychological impact of quarantine and how to reduce it: rapid review of the evidence. The Lancet, 395, 912-920.

Brown, S. M., Doom, J. R., Lechuga-Peña, S., Watamura, S. E., \& Koppels, T. (2020). Stress and parenting during the global COVID-19 pandemic. Child Abuse \& Neglect, 104699.

Can, E. \& Kilic, S. (2019). Preschool education: Basic problems and solution suggestions. National Education Journal, 48(1), 483-519.

Caner, Z. G., Unal, M., Apaydın, Z., Dag, A., Okur, S., Kara, E. et al. (2020). Covid-19 disease and the importance of home exercises. Journal of Medical Sciences,1(3):25-33.

Chanchlani, N., Buchanan, F., \& Gill, P. J. (2020). Addressing the indirect effects of COVID-19 on the health of children and young people. CMAJ, 192(32), E921-E927.

Cikrikci, O. (2020). "Cognitive, affective and behavioral changes in children according to parents: COVID-19 pandemic.” In: B Gencdogan (Ed.), Child and adolescent psychology during pandemic period. (First edition). (pp. 42-53). Ankara: Turkey Clinics.

Dalton, L., Rapa, E., \& Stein, A. (2020). Protecting the psychological health of children through effective communication about COVID-19. The Lancet Child \& Adolescent Health, 4(5), 346-347.

Epstein, D., Korytny, A., Isenberg, Y., Marcusohn, E., Zukermann, R., Bishop, B., ... \& Miller, A. (2020). Return to training in the COVID-19 era: The physiological effects of face masks during exercise. Scandinavian Journal of Medicine \& Science in Sports, 1-6.

Ghosh, R., Dubey, M.J., Chatterjee, S., \& Dubey, S. (2020). Impact of COVID-19 on children: Special focus on psychosocial aspect. Minerva Pediatrics, 72(3), 226-35.

Gulay, H. (2009). Peer relationships in the preschool period. Ballkesir University Journal of Social Sciences Institute, 12(22), 82-93.

Hughes, F. P. (2010). Children, play and development. USA: SAGE Publications.

Jena, P. K. (2020). Impact of pandemic COVID-19 on education in India. International Journal of Current Research (IJCR), 12(7), 12582-86.

Khan, S., \& Huremović, D. (2019). Psychology of the pandemic. In Psychiatry of Pandemics (pp. 37-44). Springer, Cham.

Kuru Gonen, N. (2020). “A compass to heal during the pandemic period”. In: D Kurum Yapicioglu (Ed.), Let’s heal during the pandemic period. pp. 19-48, Ankara: Ani publishing.

Lavigne, J. V., Arend, R., Rosenbaum, D., Smith, A., Weissbluth, M., Binns, H. J., \& Christoffel, K. K. (1999). Sleep and behavior problems among preschoolers. Journal of Developmental \& Behavioral Pediatrics, 20(3), $164-169$.

Lundy, A., \& Trawick-Smith, J. (2020). Effects of active outdoor play on preschool children's on-task classroom behavior. Early Childhood Education Journal, 1-9.

Marmarosh, C. L., Forsyth, D. R., Strauss, B., \& Burlingame, G. M. (2020). "The psychology of the COVID-19 pandemic: A group-level perspective.” Group Dynamics: Theory, Research, and Practice, 24(3), 122.

Mart, M., Alisinanoglu, F., \& Kesicioglu, O. S. (2015). An investigation of preschool teachers use of school gardens in Turkey. Online Submission, The Journal of International Social Research, 8(38), 748-754.

Mart, M., \& Kesicioglu, O. S. (2020). Parents' opinion to play at home during covid-19 pandemic. Electronic Turkish Studies, 15(4), 945-958.

MoNE General Directorate of Basic Education Preschool Education Program (2013). 
https://tegm.meb.gov.tr/dosya/okuloncesi/ooproram.pdf

Murthy, C. S., Bharti, B., Malhi, P., \& Khadwal, A. (2015). Sleep habits and sleep problems in healthy preschoolers. The Indian Journal of Pediatrics, 82(7), 606-611.

Ozer, M. (2020). Educational policy actions by the ministry of national education in the times of COVID-19. Kastamonu Education Journal, 28(3), 1124-1129.

Philip, J., \& Cherian, V. (2020). The psychology of human behavior during a pandemic. Indian Journal of Psychological Medicine, 42(4), 402-403.

Racine, N., Cooke, J. L., Eirich, R., Korczak, D. J., McArthur, B., \& Madigan, S. (2020). Child and adolescent mental illness during COVID-19: A rapid review. Psychiatry Research, 113307.

Rodriguez-JenKins, J., \& Marcenko, M. O. (2014). Parenting stress among child welfare involved families: Differences by child placement. Children and Youth Services Review, 46, 19-27.

Romero, E., López-Romero, L., Domínguez-Álvarez, B., Villar, P., \& Gómez-Fraguela, J. A. (2020). Testing the effects of COVID-19 confinement in Spanish children: The role of parents' distress, emotional problems and specific parenting. International Journal of Environmental Research and Public Health, 17(19), 69-75.

Wang, Y., Palonen, T., Hurme, T. R., \& Kinos, J. (2019). Do you want to play with me today? Friendship stability among preschool children. European Early Childhood Education Research Journal, 27(2), 170-184.

WHO. (2020). Advice on using masks in the context of COVID-19. Online: www.skb.gov.tr

Yalcin, S. (2020). New era covid-19 pandemic and measures to be taken in dentistry. Istanbul: Quintessence Publishing. 